\title{
Peripheral neuropathy, decreased muscle strength and obesity are strongly associated with walking in persons with type 2 diabetes without manifest mobility limitations.
}

Citation for published version (APA):

van Sloten, T. T., Savelberg, H. H., Duimel-Peeters, I. G. M., Meijer, K., Henry, R. M., Stehouwer, C. D. A., \& Schaper, N. C. (2011). Peripheral neuropathy, decreased muscle strength and obesity are strongly associated with walking in persons with type 2 diabetes without manifest mobility limitations. Diabetes Research and Clinical Practice, 91(1), 32-39. https://doi.org/10.1016/j.diabres.2010.09.030

Document status and date:

Published: 01/01/2011

DOI:

10.1016/j.diabres.2010.09.030

Document Version:

Publisher's PDF, also known as Version of record

Document license:

Taverne

Please check the document version of this publication:

- A submitted manuscript is the version of the article upon submission and before peer-review. There can be important differences between the submitted version and the official published version of record. People interested in the research are advised to contact the author for the final version of the publication, or visit the DOI to the publisher's website.

- The final author version and the galley proof are versions of the publication after peer review.

- The final published version features the final layout of the paper including the volume, issue and page numbers.

Link to publication

\footnotetext{
General rights rights.

- You may freely distribute the URL identifying the publication in the public portal. please follow below link for the End User Agreement:

www.umlib.nl/taverne-license

Take down policy

If you believe that this document breaches copyright please contact us at:

repository@maastrichtuniversity.nl

providing details and we will investigate your claim.
}

Copyright and moral rights for the publications made accessible in the public portal are retained by the authors and/or other copyright owners and it is a condition of accessing publications that users recognise and abide by the legal requirements associated with these

- Users may download and print one copy of any publication from the public portal for the purpose of private study or research.

- You may not further distribute the material or use it for any profit-making activity or commercial gain

If the publication is distributed under the terms of Article 25fa of the Dutch Copyright Act, indicated by the "Taverne" license above,

Download date: 26 Apr. 2023 


\title{
Peripheral neuropathy, decreased muscle strength and obesity are strongly associated with walking in persons with type 2 diabetes without manifest mobility limitations ${ }^{\text {is }}$
}

\author{
Thomas T. van Sloten ${ }^{a, *}$, Hans H.C.M. Savelberg ${ }^{b}$, Inge G.P. Duimel-Peeters ${ }^{c}$, \\ Kenneth Meijer ${ }^{b}$, Ronald M.A. Henry ${ }^{a}$, Coen D.A. Stehouwer ${ }^{a}$, Nicolaas C. Schaper ${ }^{a}$ \\ ${ }^{a}$ Dept. of Internal Medicine, Maastricht University Medical Centre, Maastricht, The Netherlands \\ ${ }^{\mathrm{b}}$ Dept. of Human Movement Sciences, Maastricht University Medical Centre, Maastricht, The Netherlands \\ ${ }^{\mathrm{c}}$ Dept. of Integrated Care, Maastricht University Medical Centre, Maastricht, The Netherlands
}

\section{A R T I C L E I N F O}

\section{Article history:}

Received 16 May 2010

Received in revised form

21 September 2010

Accepted 27 September 2010

Published on line 20 October 2010

Keywords:

Physical activity

Walking

Muscle strength

Peripheral neuropathy

Obesity

\begin{abstract}
A B S T R A C T
Aims: We evaluated the associations of diabetic complications and underlying pathology with daily walking activity in type 2 diabetic patients without manifest mobility limitations. Methods: 100 persons with type 2 diabetes (mean age $64.5 \pm 9.4$ years) were studied. Persons with manifest mobility limitations were excluded. Possible determinants measured: peripheral neuropathy, neuropathic pain, peripheral arterial disease, cardiovascular disease, decreased muscle strength (handgrip strength), BMI, depression, falls and fear of falling. Walking activity was measured during one week with a pedometer. Functional capacity was measured with the 6 min walk test, the timed "up and go" test and a stair climbing test. Results: Prevalence of neuropathy (40\%) and obesity (53\%) was high. Persons took a median of 6429 steps/day. In multivariate regression analysis, adjusted for age and sex, neuropathy was associated with a reduction of 1967 steps/day, decreased muscle strength with 1782 steps/day, and an increase in BMI of $1 \mathrm{~kg} / \mathrm{m}^{2}$ with a decrease of 210 steps/day (all $p<0.05$ ). Decreased muscle strength and BMI, but not neuropathy, were associated with outcome of functional capacity tests in multiple regression analysis.

Conclusions: Peripheral neuropathy, decreased muscle strength and obesity are strongly associated with walking in persons with type 2 diabetes without manifest mobility limitations.
\end{abstract}

(C) 2010 Elsevier Ireland Ltd. All rights reserved.

\section{Introduction}

International guidelines state that physical exercise is one of the cornerstones in the treatment of type 2 diabetes mellitus [1]. It has been shown that physical exercise improves glycemic control, lowers blood pressure, improves lipid profile, decreases abdominal fat mass and lowers both cardiovascular morbidity and mortality [1,2]. Unfortunately, only $30-40 \%$ of persons with type 2 diabetes meet the goals for daily physical activity and long term adherence to supervised exercise programs is generally poor [3].

The failure to increase physical activity in type 2 diabetes has been explained by sociodemographic, motivational and environmental factors. An additional explanation for the relatively poor physical activity in persons with type 2 diabetes could be that the underlying pathology of diabetes (i.e. obesity) and the presence of diabetic complications have negative

\footnotetext{
Presented on annual meeting of the Diabetic Foot Study Group 2009, Bled, Slovenia at 26th of September 2009.

* Corresponding author at: Dept. of Medicine, Maastricht University Medical Centre, P. Debyelaan 25, P.O. Box 5800, 6202 AZ Maastricht, The Netherlands. Tel.: +31 06 21214590; fax: +31 0433875006.

E-mail address: t.vansloten@student.maastrichtuniversity.nl (T.T. van Sloten). 0168-8227/\$ - see front matter (C) 2010 Elsevier Ireland Ltd. All rights reserved. doi:10.1016/j.diabres.2010.09.030
} 
effects on mobility and, thereby, on daily physical activity [4]. However, the relationship between these disorders and physical activity has received only little attention.

Studies are needed which investigate whether diabetic complications and underlying pathology affect physical activity in persons with type 2 diabetes without manifest mobility limitations. In most supervised diabetic exercise programs, persons are excluded when they have major diabetic complications or severe chronic diseases, such as severe cardiac disease or severe arthritis, as these disorders have a great impact on mobility. However, diabetic participants included in exercise programs may have clinically less severe or clinically less manifest disorders, such as peripheral neuropathy and mild peripheral arterial disease. Most exercise programs do not take such disorders into account, even though these complications could also negatively affect physical activity and adherence to intervention studies. For example, a recently performed brisk walking exercise study by Praet and van Loon [5] had a high dropout rate of $60 \%$. Although persons with cardiac disease, peripheral arterial disease, orthopaedic limitations or diabetic foot ulcerations were excluded, the high dropout rate might for a large part be explained by underlying physical limitations among participants.

In this study, daily walking activity is measured. Previous research showed that walking is the physical activity most frequently engaged by persons with type 2 diabetes [2]. In addition, walking is an important physical activity as it is directly related to all-cause and CVD mortality [2].

The aim of this study is to investigate the association of diabetic complications and underlying pathology with daily walking activity in persons with type 2 diabetes without manifest mobility limitations. We hypothesise that in these persons diabetic complications and underlying pathologies negatively affect walking activity.

\section{Subjects, materials and methods}

\subsection{Study design and subjects}

The study was performed in the region of Maastricht, the Netherlands. The majority of diabetic patients ( $\geq 90 \%)$ in this region is treated by general practitioners (GP's). Participants were recruited from ten randomly selected general practices between September 2007 and February 2008 (these represent late summer to winter months in the Netherlands). From these practices, a random sample was chosen of 400 patients with type 2 diabetes (age $\geq 40$ years). In this sample, we selected persons without major diabetic complications and without manifest mobility limitations. The selection process was performed by the main investigator (TVS), with assistance of the GP's, using electronic patient records and questionnaires filled in by participants. Exclusion criteria were nursing home residency, hospital or psychiatric institute admission, severe cognitive limitations (as diagnosed by the patients' GP) and comorbidities that have a major negative effect on mobility: a history of myocardial infarction $<6$ months prior to the start of the study, dyspnea or angina pectoris (New York Heart Association (NYHA) class III or IV), any cerebrovascular accident with residual motor symptoms, Parkinson's disease, corrected vision less than 0.5 (assessed with an eye chart), any surgical procedure $<3$ months prior the start of the study, presence of rheumatologic disease, active foot ulcer, any amputation exceeding toes and the presence of limited mobility. Limited mobility was assessed by asking persons to report difficulty (none, a little, some, much difficulty or inability) in walking ( $400 \mathrm{~m}$ ) and climbing stairs (ten steps) as described by Gregg et al. [4]. Limited mobility was defined as much difficulty or inability to perform either task.

The study was approved by the local ethics committee of the Maastricht University Medical Centre and all participants gave written informed consent.

\subsection{Assessment of diabetic complications and related pathology}

Peripheral neuropathy was classified according to the Clinical Neurological Examination (CNE) score in which a score $\geq 5$ indicates the presence of peripheral neuropathy [6]. In short, the CNE score is determined by examining the Achilles tendon reflex, vibration awareness, sharp-blunt discrimination, touch sense, position sense of the hallux and manual assessment of extensor muscle strength of the hallux and flexor muscle strength of the foot in which all items are scored as either normal, impaired or absent (0-2 points). In addition, the scoring of light touch sense was related to the anatomical level below which it is impaired (toe, mid-foot, ankle, mid-calf and knee) (0-5 points). The presence of neuropathic pain was assessed by the DN-4 questionnaire [7].

Intermittent Claudication (IC) was evaluated using the San Diego Claudication Questionnaire [8]. The Ankle Brachial Index (ABI) was measured with a hand-held doppler device and a sphygmomanometer according to international standards [9]. Participants were classified as having peripheral arterial disease (PAD) if the ABI was $<0.90$ or in the presence of IC. Cardiovascular disease (CVD) was defined as a history of stroke, transient ischemic attack, acute myocardial infarction, angina pectoris and/or heart failure.

Hand grip strength was used as a measure of muscle strength [10] and was measured three times, both at the right and the left side, according to the recommendations of the American Society of Hand Therapists [11] using a Jamar dynamometer (Sammons Preston Inc., Bollingbrook, IL, USA). The sex specific 20th percentiles were used as cut-off points representing the presence of decreased muscle strength.

The seven item depression subscale of the Hospital Anxiety and Depression Scale questionnaire was used to screen for symptoms of depression [12]. The presence of mild or severe symptoms of depression was determined using an eight point cut-off [12].

\subsection{Assessment of functional capacity and daily walking activity}

The timed "up and go" test (TUGT), the stair climbing test (time needed to walk up and down 8 flights of stairs without using the handrail) and the 6 Minutes Walk Test (6MWT) were used as measures of functional capacity [13]. The 6MWT 
measures the distance that a patient can quickly walk on a flat, hard surface in a period of $6 \mathrm{~min}$.

Physical activity was determined by two methods: a piezoelectric pedometer (the New Lifestyle 2000 pedometer, New lifestyles Inc., Lee's Summit, MO, USA) to measure daily walking activity and the PASE (Physical Activity Scale for the Elderly) questionnaire to evaluate the frequency of different physical activities (e.g. walking or cycling) [14].

The pedometer was clipped to the clothing of the participant in a horizontal position at the waist, half way between the belly button and hip. All participants were instructed to wear the pedometer constantly for seven days from the moment they got up until they went to bed, except while bathing, and were encouraged to maintain their normal routine. In addition, participants were instructed to report, in a diary, the time of awakening, bedtime, and the hours and reason for not wearing the pedometer. Participants were blinded to the daily step count and after the seven day period the pedometer was collected at the participants' home. Mean daily step count was calculated by averaging daily step counts over the 7-day study period.

To test the accuracy of the pedometer a tri-axial accelerometer (Dynaport Minimod, McRoberts, The Hague, the Netherlands; range $\pm 2 \mathrm{~g}$, sample frequency $100 \mathrm{~Hz}$ ), attached to the dorsal side of the lower trunk, was used. During the $6 \mathrm{MWT}$ we compared, in all participants, steps counted by the accelerometer and the pedometer. Accelerometer data was analysed for step detection according to the method described by Zijlstra and Hof [15]. To compare steps counted by the pedometer and the accelerometer during the 6MWT, the
Pearson correlation coefficient was calculated and a BlandAltman plot was computed.

\subsection{Other measurements}

A questionnaire was used to obtain information about highest level of education, employment status, visual impairment, diabetes duration and treatment, use of antihypertensive medication, frequency of falls during the past year and fear of falling during walking. A fall was defined as an unexpected change in position in which a person lands on the floor or ground. Recent ( $\leq 3$ months) HbA1c levels were extracted from patient records. Height, weight and waist circumference were measured according to international standards.

\subsection{Statistical analysis}

All analyses were executed with SPSS (SPSS, Chicago, IL, USA). For all analyses assumptions of parametric tests were evaluated. If necessary, log transformations were applied. We used linear regression analyses (univariate and multivariate) to identify determinants of daily walking activity (steps/ day). Because mobility in persons with type 2 diabetes is believed to be impaired by peripheral neuropathy, PAD and muscle strength $[4,16-18]$, these parameters were added first in regression analyses (enter method). We then used forward analyses to evaluate whether the following determinants had a significant contribution to this model: BMI, waist circumference (analysed as a dichotomous variable using a cut-off point of $88.0 \mathrm{~cm}$ for women and $102.0 \mathrm{~cm}$ for men), CVD,

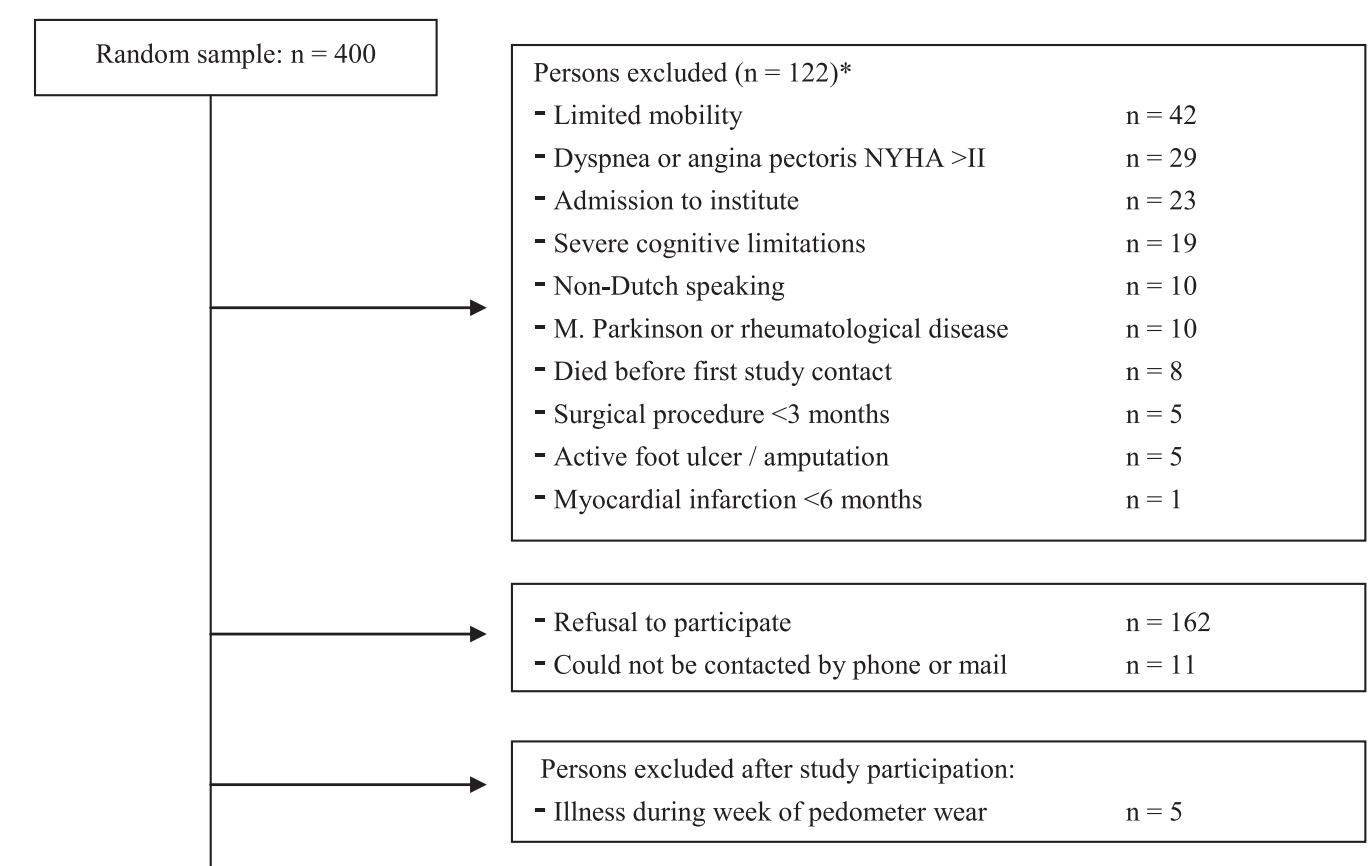

Final study sample $\mathrm{n}=100$

* Some subjects suffered of several conditions considered as exclusion criteria, therefore the sum of the frequency of different exclusion criteria exceeds 122. Abbreviations: GP = general practitioner, NYHA $=$ New York heart association, CVA = cerebrovascular event.

Fig. 1 - Flow chart of selection process. 
neuropathic pain, symptoms of depression, falls (at least one fall vs. no fall in the previous year) and fear of falling during walking. The 6MWT, the TUGT and the stair climbing test are commonly used as measures of functional capacity. Diabetic complications and underlying pathology could affect daily physical activity by reducing functional capacity. Therefore, we analysed the correlation between the aforementioned functional capacity tests and walking. In addition, multiple regression analyses were performed to investigate whether the determinants of functional capacity are similar to the determinants of walking. Peripheral neuropathy, PAD and decreased muscle strength were added first in these regression analyses, because, as described above, these factors are believed to impair mobility and in the forward analyses the same determinants were added as in the analyses described above. All multivariate analyses were adjusted for age and sex. $p$-Values of $<0.05$ were considered statistical significant.

\section{Results}

\subsection{Study population}

Of the random sample of 400 patients, 122 persons were excluded, 11 persons could not be contacted by phone and mail and 162 persons refused to participate (Fig. 1). Persons refusing to participate were evenly distributed over the ten participating practices, but were on average older (68.6 \pm 10.9 years) and more often female (54\%) compared to persons in the study population $(p<0.05)$. Five participants were excluded after study participation because they suffered from an acute illness interfering with normal activities during the week of pedometer wear. The final sample thus consisted of 100 participants. Table 1 shows the study population characteristics.

\subsection{Functional capacity}

The mean distance walked during the $6 \mathrm{MWT}$ was $537 \pm 89 \mathrm{~m}$, the mean time used to perform the TUGT was $8.3 \pm 1.8 \mathrm{~s}$, and the median [interquartile range, IQR] time to walk up and down 8 flights of stairs was 7.9 [8.3-12.6] s. Multiple regression analyses revealed that decreased muscle strength, PAD and BMI were significantly associated with the distance walked during the $6 \mathrm{MWT}$ (Table $2 \mathrm{~A}$ ). In the final regression model of the TUGT, decreased muscle strength and BMI were significantly associated with time needed to perform the test (Table 2B) and decreased muscle strength, BMI and fear of falling were significantly associated with the logarithm of time needed to perform the stair climbing test (Table 2C). In contrast, peripheral neuropathy, although associated with a marked reduction in walking activity as described below, was not significantly associated with any of these tests.

\subsection{Daily walking activity}

As evaluated with PASE questionnaire, brisk walking was the most frequently reported physical activity (41\% of all participants reported brisk walking). Other frequently
Table 1 - Study population characteristics.

$n=100$

\begin{tabular}{|c|c|}
\hline Age (years) & $64.5 \pm 9.4$ \\
\hline Sex (\% male/female) & $69.0 / 31.0$ \\
\hline Employment status (\% employed) & 26.0 \\
\hline $\begin{array}{l}\text { Education (\% highest education } \\
\text { primary school or less) }\end{array}$ & 25.0 \\
\hline Diabetes duration (years) (median, IQR) & $4.0(2.0-7.0)$ \\
\hline \multicolumn{2}{|l|}{ Treatment } \\
\hline $\begin{array}{l}\text { - Diet with or without oral hypoglycemic } \\
\text { agents (\%) }\end{array}$ & 86.0 \\
\hline - Insulin (\%) & 14.0 \\
\hline BMI $\left(\mathrm{kg} / \mathrm{m}^{2}\right)$ & $30.8 \pm 4.6$ \\
\hline $\mathrm{BMI}<25 \mathrm{~kg} / \mathrm{m}^{2}(\%)$ & 7.0 \\
\hline $\mathrm{BMI} \geq 25 \mathrm{~kg} / \mathrm{m}^{2}$ and $<30 \mathrm{~kg} / \mathrm{m}^{2}(\%)$ & 40.0 \\
\hline $\mathrm{BMI} \geq 30 \mathrm{~kg} / \mathrm{m}^{2}(\%)$ & 53.0 \\
\hline \multicolumn{2}{|l|}{ Waist circumference $(\mathrm{cm})$} \\
\hline Male & $109.6 \pm 11.7$ \\
\hline Female & $97.8 \pm 12.8$ \\
\hline \multicolumn{2}{|l|}{ Blood pressure ( $\mathrm{mmHg}$ ) } \\
\hline - Systolic pressure & $146 \pm 16$ \\
\hline - Diastolic pressure & $83 \pm 8$ \\
\hline Use of antihypertensive medication (\%) & 69.0 \\
\hline HbA1c (\%) & $6.8 \pm 0.8$ \\
\hline $\operatorname{PAD}(\%)$ & 14.5 \\
\hline CVD $(\%)$ & 23.0 \\
\hline Peripheral neuropathy (\%) & 40.0 \\
\hline Neuropathic pain (\%) & 16.0 \\
\hline \multicolumn{2}{|l|}{ Hand grip strength (kg) } \\
\hline - Men & $43.4 \pm 9.7$ \\
\hline - Women & $26.1 \pm 4.9$ \\
\hline Mild-severe depressive symptoms (\%) & 17.0 \\
\hline Falls (\% reporting $\geq$ one fall in previous year) & 10.0 \\
\hline Fear of falling (\%) & 24.0 \\
\hline
\end{tabular}

Data are means \pm SD unless otherwise stated. Abbreviations: $\mathrm{IQR}$ = interquartile range, $\mathrm{BMI}=$ body mass index, $\mathrm{PAD}=$ peripheral arterial disease, $\mathrm{CVD}=$ cardiovascular disease.

reported activities were cycling (28\%) and fitness training (14\%). Out of a 700 person-days of pedometer wear, 676 days were available for the present analyses as on 24 days participants forgot to wear the pedometer (self-reported wear time). Mean time of pedometer wear was $14.9 \pm 1.1 \mathrm{~h} /$ day. The median [IQR] of steps/day was: 6429 [4517-8573]. The correlation coefficient between steps counted by the pedometer and the accelerometer was $0.96(p<0.001)$. The Bland-Altman plot showed that the difference of steps counted by both devices was within $2 \%$ of mean steps counted, except for five participants (plot not shown). The reason for the large deviation (between $5 \%$ and $13 \%$ of mean steps counted) in these five participants could not be determined. The correlation between physical activity as measured with the PASE questionnaire and the number of steps/day was low, $r=0.30$ $(p<0.05)$. The correlation coefficient between the 6MWT and walking activity was $-0.37(p<0.001)$, between the TGUT and walking activity $-0.37(p<0.001)$ and between stair climbing and walking activity $-0.36(p<0.001)$.

\subsection{Determinants of walking}

In univariate regression analyses, daily walking activity decreased significantly with BMI, waist circumference, pe- 
Table 2 - Final model regression analysis with diabetic complications and underlying pathology as determinants of 6MWT, TUGT, stair climbing test and steps/day.

\begin{tabular}{|c|c|c|c|}
\hline Determinant & \multicolumn{2}{|c|}{ Unstandardized $\beta(95 \% \mathrm{CI})^{\mathrm{a}, \mathrm{b}}$} & $p$-Value \\
\hline \multicolumn{4}{|l|}{ (A) $6 \mathrm{MWT}$} \\
\hline PAD vs. no PAD & -69.3 & $(-104.9 ;-34.2)$ & $<0.005$ \\
\hline Peripheral neuropathy vs. no neuropathy & -30.4 & $(-63.2 ; 2.5)$ & 0.07 \\
\hline Decreased muscle strength vs. no decreased muscle strength & -69.6 & $(-104.9 ;-34.2)$ & $<0.001$ \\
\hline BMI & -5.4 & $(-8.3 ;-2.5)$ & $<0.005$ \\
\hline \multicolumn{4}{|l|}{ (B) TUGT } \\
\hline PAD vs. no PAD & 0.40 & $(-0.50 ; 1.30)$ & 0.38 \\
\hline Peripheral neuropathy vs. no neuropathy & 0.46 & $(-0.19 ; 1,11)$ & 0.17 \\
\hline Decreased muscle strength vs. no decreased muscle strength & 1.52 & $(0.82 ; 2.22)$ & $<0.001$ \\
\hline Fear of falling vs. no fear of falling & 0.61 & $(-0.07 ; 1.30)$ & 0.08 \\
\hline BMI & 0.09 & $(0.04 ; 0.15)$ & $<0.005$ \\
\hline \multicolumn{4}{|l|}{ (C) Stair climbing ${ }^{c}$} \\
\hline PAD vs. no PAD & 0.03 & $(-0.03 ; 0.09)$ & 0.35 \\
\hline Peripheral neuropathy vs. no neuropathy & 0.01 & $(-0.03 ; 0.05)$ & 0.54 \\
\hline Decreased muscle strength vs. no decreased muscle strength & 0.10 & $(0.05 ; 0.14)$ & $<0.001$ \\
\hline Fear of falling vs. no fear of falling & 0.05 & $(0.02 ; 0.09)$ & $<0.05$ \\
\hline BMI & 0.01 & $(0.002 ; 0.10)$ & $<0.005$ \\
\hline \multicolumn{4}{|l|}{ (D) Steps/day } \\
\hline PAD vs. no PAD & -1453 & $(-3387 ; 481)$ & 0.14 \\
\hline Peripheral neuropathy vs. no neuropathy & -1967 & $(-3421 ;-513)$ & $<0.05$ \\
\hline Decreased muscle strength vs. no decreased muscle strength & -1782 & $(-3348 ;-217)$ & $<0.05$ \\
\hline BMI & -210 & $(-337 ;-83)$ & $<0.005$ \\
\hline \multicolumn{4}{|l|}{$\begin{array}{l}R^{2} \text { model } A=0.51, R^{2} \text { model } B=0.53, R^{2} \text { model } C=0.65, R^{2} \text { model } D= \\
\text { disease, } B M I=\text { body mass index, TUGT = timed "up and go" test. } \\
\text { a Data are adjusted for age and sex. } \\
\text { b Data are presented unadjusted for mean time of pedometer wear. } \\
\text { c Data are log transformed. }\end{array}$} \\
\hline
\end{tabular}

ripheral neuropathy, PAD and decreased muscle strength (Table 3). In the final regression model, which included PAD, peripheral neuropathy, decreased muscle strength and BMI, and which was adjusted for age and sex, persons with peripheral neuropathy took 1967 (95\% CI -3421 to -513 , $p<0.05)$ steps/day less than persons without peripheral neuropathy, persons with decreased muscle strength took $1782(-3348$ to $-217, p<0.05)$ steps/day less than persons without decreased muscle strength and an increase in BMI of
$1 \mathrm{~kg} / \mathrm{m}^{2}$ was associated with a decrease in steps of 210 ( -337 to $-83, p<0.005$ ) per day (Table 2D). Adjusting the number of steps per day for mean time of pedometer wear did not affect the outcome of either univariate or multivariate analyses (data not shown). We evaluated whether factors, other than diabetic complications and underlying pathology, are associated with physical activity. These analyses showed that age and the use of antihypertensive medication were significantly associated with steps/day (Table 4).

Table 3 - Univariate analyses with diabetic complications and underlying pathology as possible determinants of steps/ day.

\begin{tabular}{|c|c|c|c|}
\hline \multirow{2}{*}{$\begin{array}{l}\text { Determinant } \\
\text { BMI }\end{array}$} & \multicolumn{2}{|c|}{ Standardized $\beta(95 \% \mathrm{CI})^{\mathrm{a}, \mathrm{b}}$} & \multirow{2}{*}{$\frac{p \text {-Value }}{<0.05}$} \\
\hline & -0.21 & $(-0.41 ;-0.01)$ & \\
\hline \multicolumn{4}{|l|}{ Waist circumference } \\
\hline - Male & -0.42 & $(-0.71 ;-0.14)$ & $<0.05$ \\
\hline - Female & -0.01 & $(-0.37 ; 0.34)$ & 0.94 \\
\hline PAD vs. no PAD & -0.23 & $(-0.45 ;-0.01)$ & $<0.05$ \\
\hline CVD vs. no CVD & -0.16 & $(-0.35 ; 0.04)$ & 0.12 \\
\hline Peripheral neuropathy vs. no neuropathy & -0.39 & $(-0.58 ;-0.21)$ & $<0.001$ \\
\hline Neuropathic pain vs. no neuropathic pain & -0.04 & $(-0.24 ; 0.17)$ & 0.72 \\
\hline Reduced muscle strength vs. no Decreased muscle strength & -0.30 & $(-0.50 ;-0.11)$ & $<0.005$ \\
\hline Symptoms of depression vs. no symptoms of depression & -0.04 & $(-0.24 ; 0.16)$ & 0.70 \\
\hline Fall(s) vs. no fall in previous year & -0.08 & $(-0.28 ; 0.13)$ & 0.46 \\
\hline Fear of falling vs. no fear of falling & -0.16 & $(-0.36 ; 0.04)$ & 0.11 \\
\hline
\end{tabular}


Table 4 - Univariate analyses of factors other than diabetic complications and underlying pathology as possible determinants of steps/day.

\begin{tabular}{|c|c|c|c|}
\hline \multirow{2}{*}{$\begin{array}{l}\text { Determinant } \\
\text { Male vs. female }\end{array}$} & \multicolumn{2}{|c|}{ Standardized $\beta(95 \% \mathrm{CI})^{\mathrm{a}, \mathrm{b}}$} & \multirow{2}{*}{$\frac{p \text {-Value }}{0.87}$} \\
\hline & 0.02 & $(-0.22 ; 0.18)$ & \\
\hline Age & -0.32 & $(-0.51 ;-0.13)$ & $<0.005$ \\
\hline Unemployed vs. employed & -0.17 & $(-0.37 ; 0.03)$ & 0.09 \\
\hline Education primary school or less vs. >primary school & -0.12 & $(-0.32 ; 0.08)$ & 0.25 \\
\hline Insulin vs. diet with or without oral hypoglycemic agents & -0.17 & $(-0.37 ; 0.03)$ & 0.09 \\
\hline Diabetes duration & 0.11 & $(-0.09 ; 0.31)$ & 0.26 \\
\hline \multicolumn{4}{|l|}{ Blood pressure } \\
\hline - Systolic pressure & -0.001 & $(-0.20 ; 0.20)$ & 0.99 \\
\hline - Diastolic pressure & 0.15 & $(-0.05 ; 0.35)$ & 0.14 \\
\hline Antihypertensive medication vs. no antihypertensive medications & -0.24 & $(-0.43 ;-0.04)$ & $<0.05$ \\
\hline $\mathrm{HbA1c}$ & -0.08 & $(-0.29 ; 0.12)$ & 0.42 \\
\hline LDL cholesterol & 0.10 & $(-0.12 ; 0.31)$ & 0.38 \\
\hline HDL cholesterol & 0.15 & $(-0.06 ; 0.37)$ & 0.16 \\
\hline Triglycerides & 0.01 & $(-0.21 ; 0.22)$ & 0.95 \\
\hline
\end{tabular}

\section{Discussion}

The aim of this study was to investigate the associations of diabetic complications and underlying pathology with daily walking activity in persons with type 2 diabetes without manifest mobility limitations. A population of persons with type 2 diabetes treated in primary care was selected with a mean age of 64.5 years, a relatively short diabetes duration (median 4 years) and good glycemic control (mean HbA1c $6.8 \%$ ). However, the prevalence of in particular peripheral neuropathy (40\%) and obesity (BMI $>30 \mathrm{~kg} / \mathrm{m}^{2} ; 53 \%$ ) was high.

Using an accurate pedometer, we found that diabetic persons took around 6500 steps/day, which is clearly below the recommended level of 10,000 steps/day [19]. Peripheral neuropathy and decreased muscle strength were associated with a marked reduction of walking activity (approximately 1950 and 1800 steps/day), and a $1 \mathrm{~kg} / \mathrm{m}^{2}$ increase in BMI was associated with a decrease in steps of around 200 per day. The association between three commonly used tests to measure functional capacity (brisk walking, stair climbing and standing up from chair) and walking activity was relatively low. Decreased muscle strength and obesity were associated with a decrease in functional capacity in these three different tests. However, peripheral neuropathy, although strongly associated with walking, was not associated with decreased functional capacity.

Innovative aspects of this study are the use of a validated pedometer to assess walking activity continuously during 7 days and the determination of the effect of several diabetesrelated pathologies on daily activity in a relatively healthy population of diabetic subjects. Although this study gives new insights into the causes of physical inactivity in daily life in type 2 diabetes, it has several limitations. Firstly, some potential determinants of physical activity were not assessed, including arthritis, diastolic dysfunction and cognitive impairments. In addition, we did not measure other possible determinants than diabetic complications or underlying pathologies, such as sociodemographic, motivational and environmental factors. This may explain the low $R^{2}$ value of
0.30 in our model of determinants of daily walking activity, i.e. a large part of the variability in daily step count is explained by other factors than the ones included in the model (age, sex, peripheral neuropathy, decreased muscle strength, BMI and PAD). Secondly, the study has a limited sample size. Thirdly, muscle strength was measured as hand grip strength, but we did not assess muscle strength of the legs. Finally, the results of this study cannot be generalized to diabetic patients with mobility limitations, as the aim of this study was to evaluate physical activity in persons without manifest mobility limitations.

The inexpensive and easily to administered pedometer is an attractive method to study walking activity in persons with diabetes. Previous research showed that walking is the physical activity most frequently engaged by persons with type 2 diabetes [2], which we also observed in our patients. Earlier studies showed convergent and construct validity of pedometers to assess physical activity $[20,21]$. In this study, the pedometer correlated moderately with the PASE questionnaire. Previous research found comparable results [20]. However, to our knowledge, pedometers have not been validated in persons with type 2 diabetes. Gait disorders, obesity and slow walking speed, all more prevalent in persons with diabetes, can affect the accuracy of the pedometer [22]. Therefore, we evaluated the accuracy of this device using a triaxial accelerometer. An tri-axial accelerometer is accurate in detecting steps $[15,23]$. This study showed that the New Lifestyle 2000 pedometer is as accurate as the accelerometer in detecting steps under laboratory conditions in persons with type 2 diabetes without manifest mobility limitations. Participants took around 6500 steps/day; recently proposed indices consider 6500 steps/day as 'low active' [24]. Tudor-Locke et al. reported that the mean steps/day was 6662 in a sample of 160 persons with type 2 diabetes living in the USA [19], which is comparable to the 6500 steps/day found in our sample.

Because of the cross-sectional design of this study no direct inferences can be made about the causal relationship between the determinants found and walking. However, loss of walking activity is most likely both the cause and the consequence of the determinants found. In this concept, there is a negative 
spiral with physical inactivity leading to different complications, which in turn affect physical activity. Physical inactivity results in reduced muscle strength, increased weight and worse glycemic control, culminating in a higher risk of diabetic complications [1]. On the other hand, the determinants found are themselves probably also a cause of physical inactivity.

Although peripheral neuropathy and its associated loss in peripheral sensation have been well described in the literature, only in recent years attention has been paid to the effects of peripheral neuropathy on mobility. It has become apparent that peripheral neuropathy is associated with reduced muscle strength, decrements in balance, gait abnormalities and an increased risk of falling, all of which affect the ability to be physically active [18]. Also decreased muscle strength and obesity have been associated with limited mobility [16] and in our patients decreased muscle strength was associated with a reduction in both functional capacity and daily walking activity, independent of the presence neuropathy. Persons with type 2 diabetes have both lower muscle strength and muscle quality (defined as the ratio of strength to the corresponding muscle mass in kilograms) compared to persons without diabetes [17]. Factors contributing to this are, next to peripheral neuropathy and physical inactivity, possibly a direct effect of hyperglycemia, (subclinical) PAD, and the presence of high levels of inflammatory cytokines.

Peripheral neuropathy was associated with a marked reduction in daily walking activity, however it was, in contrast to BMI and decreased muscle strength, not associated with outcome of functional capacity tests. A possible explanation is that peripheral neuropathy only affects mobility in challenging environments (i.e. in daily life) and not under ideal, standard conditions (i.e. walking on a flat, regular surface as during the $6 \mathrm{MWT}$ ). This is in accordance with previous gait analysis studies. Menz et al. [25] showed that step-time variability, which has been associated with falls [25], only differed between diabetic persons with peripheral neuropathy and healthy controls if walking on a irregular surface and not on a level surface. In accordance, Allet et al. [26] showed that when changing the walking surface from tar to stones, gait parameters deteriorate more markedly in diabetic persons with peripheral neuropathy. However, some studies did find a relationship between peripheral neuropathy and mobility limitations under ideal, standard conditions $[18,27]$ and this topic needs further research.

In conclusion, this study demonstrates that in persons with type 2 diabetes without manifest mobility limitations, peripheral neuropathy, decreased muscle strength and obesity are strongly associated with loss of walking activity. This suggests that a great number of persons with diabetes are affected in their capacity to be physically active because of the presence of diabetes-related pathologies. More research is needed to evaluate whether failure to recognise these disorders is one of the factors explaining the low success rate of exercise intervention programmes in diabetes.

\section{Conflict of interest}

The authors declare that they have no conflict of interest.
[1] Sigal RJ, Kenny GP, Wasserman DH, Castaneda-Sceppa C, White RD. Physical activity/exercise and type 2 diabetes: a consensus statement from the American Diabetes Association. Diabetes Care 2006;29:1433-8.

[2] Gregg EW, Gerzoff RB, Caspersen CJ, Williamson DF, Narayan KM. Relationship of walking to mortality among US adults with diabetes. Arch Intern Med 2003;163: 1440-7.

[3] Morrato EH, Hill JO, Wyatt HR, Ghushchyan V, Sullivan PW. Physical activity in U.S. adults with diabetes and at risk for developing diabetes, 2003. Diabetes Care 2007;30:203-9.

[4] Gregg EW, Beckles GL, Williamson DF, Leveille SG, Langlois JA, Engelgau MM, et al. Diabetes and physical disability among older U.S. adults. Diabetes Care 2000;23:1272-7.

[5] Praet SF, van Loon LJ. Exercise: the brittle cornerstone of type 2 diabetes treatment. Diabetologia 2008;51:398-401.

[6] Valk GD, Nauta JJ, Strijers RL, Bertelsmann FW. Clinical examination versus neurophysiological examination in the diagnosis of diabetic polyneuropathy. Diabet Med 1992;9:716-21.

[7] Bouhassira D, Attal N, Alchaar H, Boureau F, Brochet B, Bruxelle J, et al. Comparison of pain syndromes associated with nervous or somatic lesions and development of a new neuropathic pain diagnostic questionnaire (DN4). Pain 2005;114:29-36.

[8] Criqui MH, Denenberg JO, Bird CE, Fronek A, Klauber MR, Langer RD. The correlation between symptoms and noninvasive test results in patients referred for peripheral arterial disease testing. Vasc Med 1996;1:65-71.

[9] Mohler IIIrd ER. Peripheral arterial disease: identification and implications. Arch Intern Med 2003;163:2306-14.

[10] Lauretani F, Russo CR, Bandinelli S, Bartali B, Cavazzini C, Di Iorio A, et al. Age-associated changes in skeletal muscles and their effect on mobility: an operational diagnosis of sarcopenia. J Appl Physiol 2003;95:1851-60.

[11] Mathiowetz V, Weber K, Volland G, Kashman N. Reliability and validity of grip and pinch strength evaluations. J Hand Surg [Am] 1984;9:222-6.

[12] Bjelland I, Dahl AA, Haug TT, Neckelmann D. The validity of the hospital anxiety and depression scale. An updated literature review. J Psychosom Res 2002;52:69-77.

[13] Enright PL. The six-minute walk test. Respir Care 2003;48:783-5.

[14] Washburn RA, Smith KW, Jette AM, Janney CA. The physical activity scale for the elderly (PASE): development and evaluation. J Clin Epidemiol 1993;46:153-62.

[15] Zijlstra W, Hof AL. Assessment of spatio-temporal gait parameters from trunk accelerations during human walking. Gait Posture 2003;18:1-10.

[16] Fang ZY, Sharman J, Prins JB, Marwick TH. Determinants of exercise capacity in patients with type 2 diabetes. Diabetes Care 2005;28:1643-8.

[17] Park SW, Goodpaster BH, Strotmeyer ES, de Rekeneire N, Harris TB, Schwartz AV, et al. Decreased muscle strength and quality in older adults with type 2 diabetes: the health, aging, and body composition study. Diabetes 2006;55: 1813-8.

[18] van Schie CH. Neuropathy: mobility and quality of life. Diabetes Metab Res Rev 2008;24(Suppl. 1):S45-51.

[19] Tudor-Locke CE, Bell RC, Myers AM, Harris SB, Lauzon N, Rodger NW. Pedometer-determined ambulatory activity in individuals with type 2 diabetes. Diabetes Res Clin Pract 2002;55:191-9. 
[20] Tudor-Locke C, Williams JE, Reis JP, Pluto D. Utility of pedometers for assessing physical activity: convergent validity. Sports Med 2002;32: 795-808.

[21] Tudor-Locke C, Williams JE, Reis JP, Pluto D. Utility of pedometers for assessing physical activity: construct validity. Sports Med 2004;34:281-91.

[22] Crouter SE, Schneider PL, Bassett Jr DR. Spring-levered versus piezo-electric pedometer accuracy in overweight and obese adults. Med Sci Sports Exerc 2005;37: 1673-9.

[23] Zijlstra W. Assessment of spatio-temporal parameters during unconstrained walking. Eur J Appl Physiol 2004;92:39-44.
[24] Tudor-Locke C, Bassett Jr DR. How many steps/day are enough? Preliminary pedometer indices for public health. Sports Med 2004;34:1-8.

[25] Menz HB, Lord SR, St George R, Fitzpatrick RC. Walking stability and sensorimotor function in older people with diabetic peripheral neuropathy. Arch Phys Med Rehabil 2004;85:245-52.

[26] Allet L, Armand S, de Bie RA, Pataky Z, Aminian K, Herrmann FR, et al. Gait alterations of diabetic patients while walking on different surfaces. Gait Posture 2009;29:488-93.

[27] Dolan NC, Liu K, Criqui MH, Greenland P, Guralnik JM, Chan $\mathrm{C}$, et al. Peripheral artery disease, diabetes, and reduced lower extremity functioning. Diabetes Care 2002;25:113-20. 